\title{
Body Mass Index, Physical Activity, Dietary Intake, Serum Lipids and Blood Pressure of Middle-Aged Japanese Women Living in a Community in the Goto Archipelago
}

\author{
Setsuko Ohmura ${ }^{1,3)}$, Kazuhiko Moji ${ }^{2)}$, Kiyoshi Aoyagi' ${ }^{1)}$, Itsuro Yoshimi' ${ }^{1}$, \\ Yuichiro Yahata $^{1)}$, Tai-ichiro Takemoto ${ }^{1)}$, Nobuo Iwai ${ }^{4)}$, Nobuo Yoshiike ${ }^{5)}$, \\ Chigusa Date ${ }^{6)}$ and Heizo Tanaka ${ }^{5)}$ \\ 1) Department of Public Health, Nagasaki University School of Medicine \\ 2) Nagasaki University School of Health Sciences \\ 3) Nagasaki Women's Junior College \\ 4) Chugoku Society for Labor Health, Tottori Medical Office \\ 5) Division of Adult Health Science, National Institute of Health and Nutrition \\ 6) Department of Public Health, Osaka City University School of Medicine
}

\begin{abstract}
Mortality in the Goto archipelago region of the Nagasaki prefecture in Japan is higher than the Japanese average. In this study, we investigated dietary intake, habitual physical activities, systolic and diastolic blood pressure, serum total cholesterol and high-density lipoprotein cholesterol of middle-aged women in the Narao community in the Goto archipelago. We compared these parameters with a Japanese sample, and analyzed the results according to body mass index (BMI) and age. The mean BMI of Narao women was higher than that of the Japanese sample. Serum cholesterol and blood pressure of Narao women correlated with BMI. However, dietary intake and physical activities did not differ between normal- and over-weight Narao women. The higher serum total cholesterol and diastolic blood pressure of Narao women, relative to the Japanese sample, could be explained by the presence of overweight women in the Narao community. However, dietary and behavioral factors associated with higher BMIs could not be clarified in this cross-sectional study. J Physiol Anthropol 21 (1): 21-28, 2002 http:// www.jstage.jst.go.jp/en/
\end{abstract}

Keywords: body mass index, blood pressure, serum lipids, food intake, physical activity.

\section{Introduction}

Life expectancy of Japanese females is among the highest in the world, and approaching 84 years in 1998 (Ministry of Health and Welfare, 1999). There is, however, a regional variation of death rates in Japan. The mortality rate in the Goto archipelago in the Nagasaki Prefecture (Fig. 1) is higher than the Japanese average. In 1998, the age-adjusted death rate among females in the Narao township of the northern Goto archipelago was $1,127.8$ per 100,000 , which was 1.4 times higher than the 784.4 per 100,000 rate for the overall Nagasaki Prefecture (Nagasaki Prefectural Government, 1998). Life expectancy of females on the northern Goto archipelago was 79.84 years, which is 0.83 years shorter than the Japanese average (80.67) (data between 1983 and 1987, Hushimi and Kamata, 1993). Although the main cause of high mortality in the Goto archipelago is cancer, mortality due to cardiovascular diseases is also higher than the Japanese average.

In order to elucidate the relationship between cardiovascular risk factors, food and nutrient intake, physical activity, and body mass of middle-aged women in the Goto archipelago, we analyzed a cross-sectional data set from the Narao community. The study was conducted as part of a nation-wide epidemiological survey by the Japanese Lifestyle Monitoring Study Group (the JLM study) (Yoshiike, 1997). The JLM study focused on 13 areas throughout Japan (Tanihara et al., 1999). We compared cardiovascular risk factors with a Japanese sample, which is drawn from the JLM Study, and analyzed the results according to body mass index (BMI) and age. 


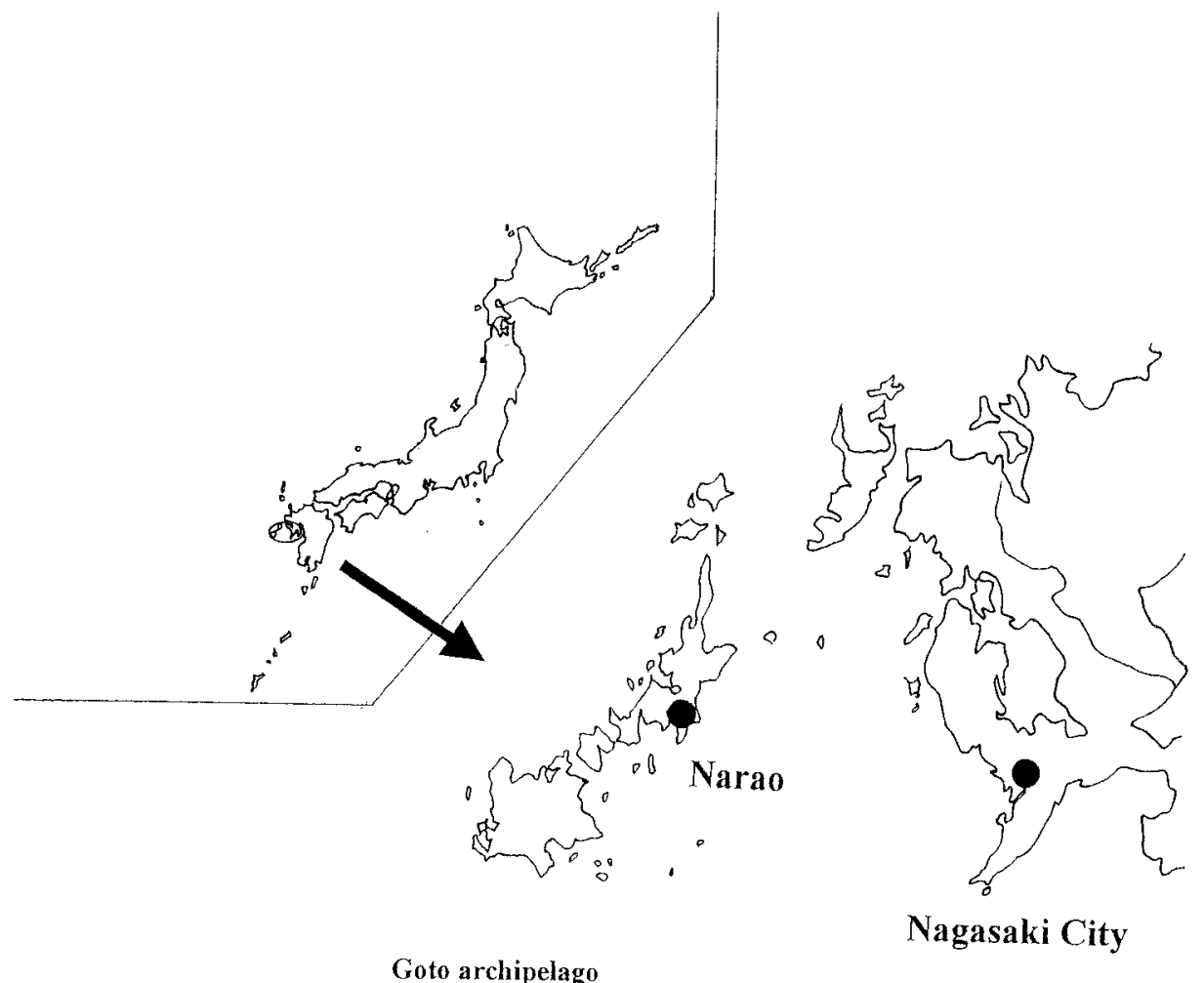

Fig. 1 Geographic location of the survey site, Narao in Goto archipelago, Nagasaki, Japan

\section{Subjects and Methods}

The study was conducted in the Narao area on Nakadoori Island in the Goto archipelago. Dietary pattern and food intake, daily habitual activity, body mass, blood pressure, and serum cholesterol of 189 women between 40 and 69 years of age were surveyed. Subjects were selected from the resident registration records of the Narao area. In 1992 there were 895 women aged between 40 and 69 years in this community. About $30 \%$ of women in their 50 s and 60 s were randomly selected from the registry and were sent an invitation letter to participate in the study. An invitation letter was sent to all female residents in their 40s because a lower participation rate was expected for this age group. A total of 189 (21\%) of Narao women between 40 and 69 years of age participated in the study. They comprised 55 women aged 40-49, 71 women aged 50-59, and 63 women aged $60-69$ years.

The Narao area is famous for round haul-net fishing and in 1983 there were eleven companies operating round haul-net fishing, and more than 1,800 fishermen and sailors employed in the industry (Yoshiki, 1983; Tsuda, 1981). Fishing remains the main industry and source of income in this area. Because round haul-net fishing is practiced exclusively by men, housewives in the Narao area tend to mostly stay at home. Although farming land is limited as the island is mountainous, many housewives also practice subsistence dry land farming for selfconsumption, made necessary by poor transportation and relatively expensive market prices. The main crops are vegetables and beans. Round haul-net fishing became economically less attractive in the 1980s and 1990s, and many young people migrated away from the region. Transportation of people and goods has improved and the Narao area has subsequently changed considerably. A cash economy has penetrated into the area, and some women have part-time jobs. The tradition of small farming nonetheless continues.

\section{Arterial blood pressure}

Arterial blood pressure was measured by physicians using sphygmomanometers. The physicians were trained by watching training videotapes designed for the Hypertension Detection and Follow-up Program. The protocol of blood pressure measurement of the JLM study (Tanaka, 1992) was followed.

\section{Serum cholesterol}

Blood samples were collected in the Narao hospital in the early morning in the over-night fasted state. Serum samples were sent to the laboratory of the Osaka Medical 
Center for Cancer and Cardiovascular Diseases for measurement of total cholesterol and high-density lipoprotein (HDL) cholesterol. The methods have been described elsewhere (Tanaka, 1992). This laboratory has participated in the CDC-NHLBI lipid standardization program.

\section{Daily activities and required physical strength}

Daily activities over the previous 12 months and the required physical strength were recorded by the recall method (Iwai et al., 2000). Daily activities were classified into; 1) habitual leisure-time physical activity (LTPA), 2) work, including housekeeping activities and commuting, 3) sleeping, and 4) residual time. A multiple of the resting metabolic rate (MET) was used as the unit to measure the intensity of physical activity.

Frequency, intensity, and average actual duration of LTPA were recorded for six two-month periods prior to the survey using a questionnaire similar to the Minnesota LTPA questionnaire (Taylor et al., 1978). Since the study was done mainly in June, activities of July and August of the previous year were asked first, then followed by the activities of the following two months. This procedure was repeated continuously up to May and June of the survey year. Validity of this method has been discussed elsewhere (Iwai et al., 2000).

Intensity of LTPA was classified as light (2.5 METs), moderate (4.5 METs), hard (6.5 METs), or very hard (8.5 METs). The LTPA score (METs*min/day) of each subject was calculated by the following procedure: 1) For each activity in the LTPA category (for example, jogging), the LTPA score during a two-month interval was first calculated by multiplying intensity, duration and frequency of the activity, 2) The annual LTPA score (METs*min/year) of that activity was calculated by adding all six two-month figures, 3) The total annual LTPA score for all activities in the LTPA category was calculated by summing up all the activities undertaken by each subject (for example, jogging, walking, playing volleyball), 4) The daily LTPA score was calculated by dividing this figure by 365 .

Frequency, intensity, and duration of work for each subject were then recorded in a manner similar to that used for LTPA. Intensity of work was classified into sedentary (1.5 METs), standing or walking (2.5 METs), moderately strenuous (4.5 METs), or strenuous (7.5 METs). On-the-job physical activity (JPA) scores were accordingly calculated. The total daily physical activity (TDPA) score for each subject was calculated by summing physical activity scores during leisure time, on-the-job, sleep (0.75 METs), and residual time (1.5 METs).

\section{Food and nutrient intake}

The 24-hour recall method of food intake was conducted by trained dieticians using a variety of food models and photographs. The food intake survey also followed the protocol of the JLM study (Tanaka, 1992) and that of the NHANES protocol (Centers for Disease Control and Prevention, 1994). Nutrient and energy intakes were calculated using the Standard Food Composition Tables (Science and Technology Agency, Japan, 1986). Energy and nutrient intakes were compared between Narao women and the Japanese sample and between normal-weight and over-weight Narao women. Since no data were available on daily consumption of food groups for the Japanese sample in the JLM study, we compared the results for Narao women with those of the National Nutritional Survey (NNS), Japan (Lifestyle-Related Diseases Control Health Service Bureau, 2000).

\section{Statistical analysis}

Differences in blood pressure, serum cholesterol, body mass index (BMI), food intake, and physical activity between Narao women and the Japanese sample (the JLM Study) and between normal-weight and over-weight Narao women were tested using the t-test or the ANCOVA using age as a covariate. Multiple regression analyses were performed to determine relationships of age, BMI and physical activity (LTPA or TDPA) to blood pressure and serum cholesterol, using SPSS version 10.0 software (SPSS Inc., Chicago, IL).

\section{Results}

Body mass, arterial blood pressure, and serum cholesterol

The mean age, height, weight, and BMI of the 189 women were 55 years, $153 \mathrm{~cm}, 56 \mathrm{~kg}$, and $24.1 \mathrm{~kg} / \mathrm{m}^{2}$, respectively (Table 1). The mean BMI of Narao women was significantly higher than that of the Japanese sample. The mean total cholesterol and diastolic blood pressure were higher in Narao women than in the Japanese sample. There was no significant difference in HDL cholesterol and systolic blood pressure between the two groups. These differences were also significant by ANCOVA using age as a covariate.

The mean age, height, weight, and BMI of 117 normalweight Narao women (BMI $<25 \mathrm{~kg} / \mathrm{m}^{2}$ ) were 53 years, $152 \mathrm{~cm}, 51 \mathrm{~kg}$, and $21.7 \mathrm{~kg} / \mathrm{m}^{2}$, respectively. The corresponding values for 72 over-weight Narao women (BMI $\geq 25 \mathrm{~kg} / \mathrm{m}^{2}$ ) were 57 years, $153 \mathrm{~cm}, 65 \mathrm{~kg}$, and 27.9 $\mathrm{kg} / \mathrm{m}^{2}$, respectively. The BMI of Narao women was related to age $(r=0.248, p<0.01)$ and over-weight women were significantly older than normal-weight women. Over-weight women had higher systolic and diastolic blood pressures, higher total cholesterol and lower HDL cholesterol than normal-weight women. 
Table 1 Physical characteristics, blood pressure and serum lipid profile of normal- and over-weight Narao women and Japanese sample

\begin{tabular}{|c|c|c|c|c|c|c|c|c|c|c|c|}
\hline \multirow{3}{*}{ Variable } & \multirow{3}{*}{ unit } & \multirow{2}{*}{\multicolumn{2}{|c|}{$\frac{\text { Over-weight }^{1}}{(\mathrm{n}=72)}$}} & \multirow{2}{*}{\multicolumn{2}{|c|}{$\frac{\text { Normal-weight }^{2}}{(\mathrm{n}=117)}$}} & \multirow{2}{*}{\multicolumn{2}{|c|}{$\frac{\mathrm{Narao}^{3}}{(\mathrm{n}=189)}$}} & \multirow{2}{*}{\multicolumn{2}{|c|}{$\begin{array}{c}\text { Japan }^{4} \\
(n=1006)\end{array}$}} & \multirow{3}{*}{$\begin{array}{c}1 \text { vs. } 2 \\
\text { t-test } \\
\text { p }\end{array}$} & \multirow{3}{*}{$\begin{array}{c}3 \text { vs. } 4 \\
\text { t-test } \\
\mathrm{p}\end{array}$} \\
\hline & & & & & & & & & & & \\
\hline & & Mean & S.D. & Mean & S.D. & Mean & S.D. & Mean & S.D. & & \\
\hline Age & years & 57.2 & 6.6 & 53.4 & 8.8 & 54.9 & 8.2 & & & ** & \\
\hline Height & $\mathrm{cm}$ & 152.8 & 5.0 & 152.4 & 4.8 & 152.6 & 4.9 & & & ns & \\
\hline Weight & $\mathrm{kg}$ & 65.3 & 7.4 & 50.5 & 5.3 & 56.2 & 9.5 & & & $* * *$ & \\
\hline BMI & $\mathrm{kg} / \mathrm{m}^{2}$ & 27.9 & 2.3 & 21.7 & 2.0 & 24.1 & 3.7 & 23.2 & 3.1 & $* * *$ & ** \\
\hline Systolic blood pressure & $\mathrm{mmHg}$ & 138.4 & 20.2 & 123.7 & 19.6 & 129.3 & 21.1 & 126.9 & 18.5 & $* * *$ & $\mathrm{~ns}$ \\
\hline Diastolic blood pressure & $\mathrm{mmHg}$ & 83.6 & 11.2 & 76.0 & 12.1 & 78.9 & 12.3 & 76.9 & 10.6 & $* * *$ & * \\
\hline Total-cholesterol & $\mathrm{mmol} / \mathrm{l}$ & 5.84 & 0.93 & 5.57 & 1.10 & 5.70 & 1.05 & 5.52 & 0.99 & * & * \\
\hline HDL-cholesterol & $\mathrm{mmol} / \mathrm{l}$ & 1.39 & 0.30 & 1.63 & 0.41 & 1.53 & 0.39 & 1.50 & 0.36 & $* * *$ & ns \\
\hline
\end{tabular}

BMI: body mass index; HDL: high-density lipoprotein. ${ }^{*}: \mathrm{p}<0.05,{ }^{* *}: \mathrm{p}<0.01,{ }^{* *}$ : $\mathrm{p}<0.001$, ns: not significant.

Table 2 Nutrient intake of normal- and over-weight Narao women and the Japanese sample

\begin{tabular}{|c|c|c|c|c|c|c|c|c|c|c|c|}
\hline \multirow[t]{2}{*}{ Nutrient } & \multirow[t]{2}{*}{ unit } & \multicolumn{2}{|c|}{$\frac{\text { Over-weight }^{1}}{(\mathrm{n}=72)}$} & \multicolumn{2}{|c|}{$\frac{\text { Normal-weight }^{2}}{(\mathrm{n}=117)}$} & \multicolumn{2}{|c|}{$\frac{\mathrm{Narao}^{3}}{(\mathrm{n}=189)}$} & \multicolumn{2}{|c|}{$\frac{\text { Japan }^{4}}{(n=942)}$} & \multirow{2}{*}{$\begin{array}{c}1 \text { vs. } 2 \\
\text { t-test } \\
p\end{array}$} & \multirow{2}{*}{$\begin{array}{c}3 \text { vs. } 4 \\
\text { t-test } \\
\mathrm{p}\end{array}$} \\
\hline & & Mean & S.D. & Mean & S.D. & Mean & S.D. & Mean & S.D. & & \\
\hline Energy & kcal & 1689 & 395 & 1700 & 452 & 1700 & 430 & 1780 & 488 & ns & ns \\
\hline Total-protein & g & 66.6 & 20.1 & 65.9 & 22.8 & 66.2 & 21.7 & 69.3 & 20.4 & ns & ns \\
\hline Animal-protein & $\mathrm{g}$ & 36.7 & 17.3 & 36.3 & 19.7 & 36.4 & 18.7 & 35.5 & 16.7 & ns & ns \\
\hline Total-fat & g & 42.4 & 17.2 & 47.1 & 23.2 & 45.3 & 21.2 & 49.1 & 21.3 & ns & ns \\
\hline Animal-fat & $\mathrm{g}$ & 14.9 & 10.9 & 17.7 & 13.2 & 16.6 & 12.4 & 23.2 & 13.3 & ns & $* * *$ \\
\hline Calcium & $\mathrm{mg}$ & 481 & 228 & 478 & 232 & 479 & 230 & 576 & 262 & $\mathrm{~ns}$ & $* * *$ \\
\hline Iron & $\mathrm{mg}$ & 8.4 & 3.9 & 8.5 & 3.0 & 8.4 & 3.4 & 10.3 & 4.4 & ns & $* * *$ \\
\hline Vitamin A & IU & 1991 & 1581 & 2437 & 3240 & 2267 & 2733 & 2870 & 3965 & ns & * \\
\hline Vitamin $B_{1}$ & $\mathrm{mg}$ & 0.87 & 0.30 & 0.90 & 0.42 & 0.89 & 0.15 & 0.96 & 0.4 & ns & ns \\
\hline Vitamin $B_{2}$ & mg & 1.15 & 0.47 & 1.23 & 0.74 & 1.30 & 0.65 & 1.34 & 0.51 & ns & $\mathrm{ns}$ \\
\hline Vitamin C & $\mathrm{mg}$ & 110 & 66 & 109 & 70 & 109 & 68 & 140 & 86 & ns & $* * *$ \\
\hline Salt & $\mathrm{g}$ & 9.9 & 3.3 & 10.1 & 3.6 & 10.0 & 3.5 & 11.9 & 4.6 & ns & $* * *$ \\
\hline Cholesterol & mg & 307.4 & 190.6 & 331.6 & 195.3 & 322.3 & 193.4 & 351.0 & 206.0 & ns & ns \\
\hline PUFA/SFA & & 1.09 & 0.51 & 1.05 & 0.46 & 1.06 & 0.48 & 1.03 & 0.43 & ns & ns \\
\hline Protein/Energy & $\%$ & 15.8 & 3.0 & 15.5 & 3.3 & 15.6 & 3.2 & 15.7 & 3.1 & ns & ns \\
\hline Fat/Energy & $\%$ & 22.3 & 6.3 & 24.1 & 7.8 & 23.4 & 7.3 & 24.6 & 7.3 & ns & ns \\
\hline Carbohydrate/Energy & $\%$ & 62.0 & 6.9 & 60.4 & 9.0 & 61.0 & 8.3 & 59.7 & 8.6 & ns & ns \\
\hline Number of Food & & 25.2 & 6.8 & 26.0 & 6.5 & 25.7 & 6.6 & 27.5 & 6.6 & ns & $* * *$ \\
\hline
\end{tabular}

PUFA: polyunsaturated fatty acids, SFA: saturated fatty acids, ${ }^{*}: \mathrm{P}<0.05,{ }^{* *}$ : $\mathrm{P}<0.001$, ns: not significant.

\section{Intake of energy, nutrients, and food groups}

Table 2 shows daily energy and nutrient intake for Narao women, both over-weight and normal-weight, and the Japanese sample. Narao women had lower intakes of iron, calcium, salt, vitamin A, vitamin $\mathrm{C}$, and animal fat than the Japanese sample. The mean number of food items consumed per day was 25.7 for Narao women, which was less than the Japanese sample (27.5). There was no significant difference in energy and nutrient intake between over-weight and normal-weight Narao women. Energy intake and nutrient intake did not correlate significantly with BMI.

Table 3 shows daily consumption of food groups by Narao women and results from the NNS, Japan. Narao women consumed significantly less potatoes, seeds, oils/ fats, soybean products, fruits, mushrooms, seaweed and meats than the NNS sample. The daily consumption of meats was only $43 \mathrm{~g}$ for Narao women compared to $64 \mathrm{~g}$ for the NNS sample. Narao women consumed more dairy products than individuals in the NNS sample (140 g vs. $118 \mathrm{~g})$.

There was no significant difference in consumption of any food groups between the over-weight and normalweight Narao women. Only the intake of fruit correlated with BMI $(r=0.157, \mathrm{p}<0.05)$.

\section{Physical activity}

Table 4 shows physical activity scores of over-weight and normal-weight Narao women and the Japanese sample. Results of time allocation and average intensity 
Table 3 Comparison of food groups intakes between normal- and over-weight Narao women and National Nutrition Survey (NNS), Japan

\begin{tabular}{|c|c|c|c|c|c|c|c|c|c|c|c|}
\hline \multirow[t]{2}{*}{ Food groups } & \multirow[t]{2}{*}{ unit } & \multicolumn{2}{|c|}{$\frac{\text { Over-weight }^{1}}{(\mathrm{n}=72)}$} & \multicolumn{2}{|c|}{$\frac{\text { Normal-weight }^{2}}{(\mathrm{n}=117)}$} & \multicolumn{2}{|c|}{$\frac{\mathrm{Narao}^{3}}{(\mathrm{n}=189)}$} & \multicolumn{2}{|c|}{$\begin{array}{c}\mathrm{NNS}^{4} \\
(\mathrm{n}=3134)\end{array}$} & \multirow{2}{*}{$\begin{array}{c}1 \text { vs. } 2 \\
\text { t-test } \\
p\end{array}$} & \multirow{2}{*}{$\begin{array}{c}3 \text { vs. } 4 \\
\text { t-test } \\
\mathrm{p}\end{array}$} \\
\hline & & Mean & S.D. & Mean & S.D. & Mean & S.D. & Mean & S.D. & & \\
\hline Cereals & g & 235.6 & 77.1 & 235.3 & 101.3 & 235.4 & 92.6 & 237.1 & 2.0 & ns & ns \\
\hline Potatoes & $\mathrm{g}$ & 51.8 & 63.7 & 45.5 & 68.4 & 47.9 & 66.6 & 73.3 & 3.6 & ns & $* * *$ \\
\hline Seeds & g & 0.8 & 3.8 & 0.8 & 2.6 & 0.8 & 3.1 & 2.7 & 0.8 & ns & $* * *$ \\
\hline Sugar & g & 11.0 & 11.1 & 11.5 & 9.7 & 11.3 & 10.2 & 10.4 & 0.4 & ns & ns \\
\hline Confectionery & g & 25.0 & 51.1 & 28.5 & 41.1 & 27.2 & 45.1 & 25.6 & 3.2 & ns & ns \\
\hline Oils and Fats & g & 9.1 & 7.8 & 10.7 & 10.2 & 10.1 & 9.3 & 14.6 & 2.3 & ns & $* * *$ \\
\hline Soybean products & $\mathrm{g}$ & 64.3 & 99.1 & 61.4 & 60.4 & 62.5 & 77.2 & 79.2 & 7.8 & ns & $* *$ \\
\hline Fruits & g & 153.8 & 160.3 & 113.6 & 137.6 & 128.9 & 147.6 & 154.1 & 24.3 & ns & * \\
\hline Vegetables & g & 268.5 & 168.4 & 281.5 & 181.6 & 276.5 & 176.3 & 285.8 & 14.7 & ns & ns \\
\hline Mushrooms & g & 5.3 & 18.9 & 4.4 & 11.0 & 4.7 & 14.5 & 16.0 & 1.3 & ns & $* * *$ \\
\hline Seaweeds & $\mathrm{g}$ & 2.5 & 4.4 & 2.5 & 3.4 & 2.5 & 3.8 & 7.2 & 1.0 & ns & $* * *$ \\
\hline Fishes & $\mathrm{g}$ & 111.3 & 74.4 & 104.5 & 92.9 & 107.1 & 86.1 & 101.4 & 8.2 & ns & ns \\
\hline Meats & $\mathrm{g}$ & 36.6 & 41.8 & 46.6 & 54.5 & 42.8 & 50.1 & 63.6 & 9.2 & ns & $* * *$ \\
\hline Eggs & $\mathrm{g}$ & 30.2 & 31.4 & 33.5 & 34.0 & 32.2 & 33.0 & 36.6 & 4.0 & ns & ns \\
\hline Dairy products & g & 140.5 & 154.6 & 140.0 & 145.2 & 140.2 & 148.4 & 117.5 & 3.6 & ns & * \\
\hline
\end{tabular}

${ }^{*}: \mathrm{P}<0.05,{ }^{* *}: \mathrm{P}<0.001$, ns: not significant.

Table 4 Comparison of time allocation and physical activity scores

\begin{tabular}{|c|c|c|c|c|c|c|c|c|c|c|}
\hline \multirow[t]{2}{*}{ Activity and physical activity score } & \multicolumn{2}{|c|}{$\frac{\text { Over-weight }^{1}}{(\mathrm{n}=72)}$} & \multicolumn{2}{|c|}{$\frac{\text { Normal-weight }^{2}}{(\mathrm{n}=117)}$} & \multicolumn{2}{|c|}{$\begin{array}{c}\text { Narao }^{3} \\
(n=189)\end{array}$} & \multicolumn{2}{|c|}{$\begin{array}{c}\text { Japan }^{4} \\
(\mathrm{n}=988)\end{array}$} & \multirow{2}{*}{$\begin{array}{c}1 \text { vs. } 2 \\
\text { t-test } \\
p\end{array}$} & \multirow{2}{*}{$\begin{array}{c}3 \text { vs. } 4 \\
\text { t-test } \\
\mathrm{p}\end{array}$} \\
\hline & Mean & S.D. & Mean & S.D. & Mean & S.D. & Mean & S.D. & & \\
\hline \multicolumn{11}{|l|}{ Time allocated(hours/day) } \\
\hline Work (including home making) & 5.9 & 3.0 & 6.4 & 3.0 & 6.2 & 3.0 & 7.2 & 2.8 & ns & $* * *$ \\
\hline Leisure time activities (sports, etc) & 0.4 & 0.5 & 0.3 & 0.5 & 0.3 & 0.5 & 0.2 & 0.4 & ns & * \\
\hline sleeping & 7.0 & 1.0 & 7.0 & 1.0 & 7.0 & 1.0 & 7.1 & 1.0 & ns & ns \\
\hline Other activities (residual time) & 10.8 & 3.0 & 10.3 & 3.0 & 10.5 & 3.0 & 9.5 & 2.8 & ns & $* * *$ \\
\hline \multicolumn{11}{|l|}{ Average intensity of activities (METs) } \\
\hline Work (including home making) & 2.59 & 0.61 & 2.53 & 0.53 & 2.56 & 0.56 & $(2.54)$ & - & ns & - \\
\hline Leisure time activities (sports, etc) & 3.14 & 1.10 & 3.64 & 1.32 & 3.43 & 1.25 & $(3.00)$ & - & ns & - \\
\hline sleeping & $(0.75)$ & - & $(0.75)$ & - & $(0.75)$ & - & $(0.75)$ & - & - & - \\
\hline Other activities (residual time) & $(1.50)$ & - & $(1.50)$ & - & $(1.50)$ & - & $(1.50)$ & - & - & - \\
\hline Whole day & 1.58 & 0.27 & 1.58 & 0.20 & 1.58 & 0.23 & $(1.60)$ & - & ns & - \\
\hline \multicolumn{11}{|l|}{ Physical activity score (MET*min/day) } \\
\hline JPA score & 918.8 & 588.5 & 957.1 & 458.2 & 942.5 & 510.5 & 1096.1 & 491.6 & ns & $* * *$ \\
\hline LTPA score & 64.3 & 84.8 & 58.1 & 93.6 & 60.4 & 90.2 & 36.5 & 71.9 & ns & $* * *$ \\
\hline Sleeping PA score & 311.6 & 51.7 & 313.1 & 48.8 & 312.5 & 49.8 & 319.6 & 45.1 & ns & ns \\
\hline Residual time PA score & 973.5 & 283.5 & 947.8 & 277.5 & 957.6 & 279.3 & 856.1 & 253.5 & ns & $* * *$ \\
\hline TDPA score & 2268.1 & 390.7 & 2276.0 & 287.6 & 2273.0 & 329.7 & 2308.4 & 326.9 & ns & $\mathrm{ns}$ \\
\hline
\end{tabular}

of activities (METs) are also shown. The LTPA and JPA scores of the Japanese sample were 36.5 (standard deviation [SD] 71.9) and 1096.1 (SD 491.6), respectively $(n=988)$. Narao women had significantly lower JPA scores (942.5; SD 510.5) and higher LTPA (60.4; SD 90.2) and residual time physical activity scores (957.6; SD 279.3). The TDPA score and daily average METs (TDPA scores divided by 1440 min) were 2308.4 and 1.60 for the Japanese sample and 2273.0 and 1.58 for the Narao women, respectively. There was no significant difference between the two groups.

The JPA, LTPA and TDPA scores did not differ between the normal- and over-weight Narao women. Daily average METs were 1.58 both for normal-weight and for over- 
Table 5 Correlations between age, BMI and physical activity (LTPA or TDPA) with blood pressure and serum cholesterol using multiple regression model

\begin{tabular}{lcccc}
\hline Outcome variable & Age & BMI & LTPA score & TDPA score \\
\hline Systolic blood pressure & $0.77(0.18)^{*}$ & $1.54(0.39)^{*}$ & $0.016(0.015)$ & - \\
Diastolic blood pressure & $0.20(0.11)$ & $0.89(0.24)^{*}$ & $0.018(0.010)$ & - \\
Total cholesterol & $0.69(0.38)$ & $1.72(0.83)^{*}$ & $0.012(0.033)$ & - \\
HDL-cholesterol & $0.04(0.14)$ & $-1.27(0.30)^{*}$ & $0.021(0.012)$ & - \\
Systolic blood pressure & $0.82(0.17)^{*}$ & $1.55(0.39)^{*}$ & - & $0.005(0.004)$ \\
Diastolic blood pressure & $0.25(0.11)^{*}$ & $0.88(0.24)^{*}$ & - & $0.003(0.003)$ \\
Total cholesterol & $0.69(0.37)$ & $1.66(0.83)^{*}$ & - & $0.008(0.009)$ \\
HDL-cholesterol & $0.02(0.13)$ & $-1.25(0.30)^{*}$ & - & $0.005(0.003)$ \\
\hline Data are regr
\end{tabular}

Data are regression coefficients (standard error). BMI: body mass index; LTPA: leisure-time physical activity; TDPA: total daily physical activity; HDL: high-density lipoprotein. ${ }^{*}$ : p $<0.05$.

weight women. BMI did not correlate with any of the physical activity scores. The LTPA and JPA scores changed with age with correlation coefficients of 0.162 $(p<0.05)$ and $-0.257(p<0.001)$, respectively. The JPA score decreased from 1147 in women aged 40-49 years, to 945 in women aged 50-59, and 761 women in their 60 s. The LTPA score increased from 42 at $40-49$ years, to 53 at $50-59$, and 85 in women aged 60-69 years. The TDPA score did not change significantly with age.

Correlation of age, BMI, and physical activity with blood pressure and serum cholesterol

Multiple regression analyses were performed to check effects of age, BMI and physical activity on blood pressure and serum cholesterol (Table 5). Engagement in leisuretime physical activity is reported to be associated with various healthy lifestyle factors (for example, individuals characterize themselves as being psychologically healthy and non-smoking) (Iwai, 2000). Thus, we analyzed LDPA and TDPA in two models, separately. In model 1 , the LTPA score was used as physical activity, and in model 2, the TDPA score was used. However, similar results were obtained in models 1 and 2. Age correlated significantly with systolic blood pressure. BMI correlated significantly with systolic blood pressure, diastolic blood pressure and total cholesterol, and negatively with HDL cholesterol. Neither LTPA nor TDPA correlated with systolic or diastolic blood pressure, total cholesterol or HDL cholesterol.

\section{Discussion}

Our study compared serum cholesterol, blood pressure, diet and physical activity between Narao women and a Japanese sample. These parameters were also compared between normal- and over-weight Narao women. Narao women had higher total cholesterol, higher diastolic blood pressure and higher BMIs than the Japanese sample. The BMI of Narao women positively correlated with systolic and diastolic blood pressure and total cholesterol, and negatively correlated with HDL cholesterol. Because normal-weight Narao women had similar total cholesterol levels and diastolic blood pressures to the Japanese sample, higher total cholesterol and higher diastolic blood pressure in Narao women could largely be explained by the presence of over-weight women among the Narao community. Consistent with many previous studies (Erlinger et al., 2000; Iwao et al., 2000; Salomaa et al., 1991; Denke et al., 1993; He et al., 1994; McCarron and Reusser, 1996), we found that BMI was an important risk factor for hypertension and high serum total cholesterol. Furthermore, Angelo et al. (1999) and Pietrobelli et al. (1999) reported an inverse correlation between serum HDL cholesterol and BMI in women, which was also consistent with our results.

Several studies have demonstrated that physical activity reduces hypertension, and inhibits high total cholesterol and low HDL cholesterol (Fonong et al., 1996; Wilcox et al., 2001; Marrugat et al., 1996). However, in multiple regression analyses, the LTPA or TDPA scores of Narao women did not correlate with systolic or diastolic blood pressure, or with total or HDL cholesterol. On the contrary, the LTPA score correlated with HDL cholesterol in the Japanese sample of the JLM study (Iwai, 2000). Ashton et al. (2000) found a strong relationship between frequency of leisure-time physical activity in middle-aged women and blood pressure and serum cholesterol, whereas in contrast, Salomaa et al. (1991) reported no significant correlation between HDL cholesterol and leisure-time physical activity. In Narao, $83 \%$ of households had farmland and most Narao women in the present study were cultivating food for self-consumption. Although this activity is in general very heavy, the working time and on-the-job physical activity scores of Narao women were lower than for the Japanese sample. The relationship between physical activity and blood pressure and serum cholesterol may differ between populations, between communities, or between urban and rural settings because of differences in components of physical activity from place to place. 
Angelo et al. (1999) and Dorn et al. (1997) reported that a high BMI was associated with cardiovascular risk. Hypertension, high total cholesterol and low HDL cholesterol are more closely correlated with cardiovascular disease (Jacobs et al., 1990; Kromhout, 2001). Higher blood pressure, higher total cholesterol and lower HDL cholesterol in over-weight Narao women may, at least in part, account for the high mortality from cardiovascular disease in the Goto archipelago.

Diets low in saturated fatty acids and rich in plant foods are reported to be associated with a decreased risk of cardiovascular disease (Pietinen et al., 2001; Kromhout, 2001). Although the polyunsaturated/saturated fatty acid ratio did not differ between Narao women and the Japanese sample, Narao women consumed significantly less plant foods, such as potatoes, seeds, soybean products, fruits, mushrooms and seaweed than the NNS sample. This finding may also partly explain the higher mortality rates from cardiovascular disease in the Goto archipelago.

We found no significant difference in physical activity or diet between normal- and over-weight Narao women, and dietary and behavioral factors associated with higher BMIs could not be clarified in this cross-sectional setting. Longitudinal studies are necessary to elucidate the natural history and relationships among changes of physical activity and diet, increase of BMI and changes of blood pressure and serum cholesterol in this community. Dietary and behavioral factors as well as genetic factors might have contributed to the increase in BMI over time. Food intake and work patterns have changed dramatically in the Goto archipelago over the past 50 years. However, many Narao women have not satisfactorily adapted to these rapid changes in terms of maintaining a healthy body mass. New health promotion strategies are necessary to lower the BMI and risk of cardiovascular disease in such women.

Acknowledgments The authors are grateful to the Narao women who participated in this study, and the staff and members of the Narao town office, Narao hospital, and Department of Public Health, Nagasaki University. The authors also thank Ms. Kyoko Sakitani for her valuable assistance in conducting the study. This study was supported by a Grant-in-Aid for Health Promotion Research from the Ministry of Health and Welfare of Japan.

\section{References}

Angelo P, Lee RC, Capristo E, Deckelbaum RJ, Heymsfield SB (1999) An independent, inverse association of high-density-lipoprotein-cholesterol concentration with nonadipose body mass. Am J Clin Nutr 69: 614-620
Ashton WD, Nanchahal K, Wood DA (2000) Leisure-time physical activity and coronary risk factors in women. $\mathrm{J}$ Cardiovasc Risk 7: 259-266

Centers for Disease Control and Prevention (1994) Plan and Operation of the National Health and Nutrition Examination Survey, 1988-1994. National Center for Health Statistics United States Department of Health and Human Services, MD

Denke MA, Sempos CT, Grundy SM (1993) Excess body weight. An under recognized contributor to high blood cholesterol levels in white American men. Arch Intern Med 153:1093-1103

Dorn JM, Schisterman EF, Winkelstein Jr. W, Trevisan M (1997) Body mass index and mortality in a general population sample of men and women: the Buffalo health study. Am J Epidemiol 146: 919-931

Erlinger TP, Pollack H, Appel LJ (2000) Nutrition-related cardiovascular risk factors in older people: results from the Third National Health and Nutrition Examination Survey. J Am Geriatr Soc 48: 1486-1489

Fonong T, Toth MJ, Ades PA, Katzel LI, Escandon JC, Poehlman ET (1996) Relationship between physical activity and HDL-cholesterol in healthy older men and women: a cross- sectional and exercise intervention study. Atherosclerosis 127: 177-183

He J, Klag MJ, Whelton PK, Chen JY, Qian MC, He GQ (1994) Body mass and blood pressure in a lean population in southwestern China. Am J Epidemiol 139: 380-389

Hushimi K, Kamata M (1993) Life Span: the sphere of second medical life table death analysis. Jumyo-GakuKenkyujo, Tokyo, pp. 87

Iwai N, Yoshiike N, Saitoh S, Nose T, Kushiro T, Tanaka H, the Japan Lifestyle Monitoring Study Group (2000) Leisure-time physical activity and related lifestyle characteristics among middle-aged Japanese. J Epidemiology 10: 226-233

Iwao N, Iwao S, Muller DC, Elahi D, Shimokata H, Andres $R$ (2000) A test of recently proposed BMI standards with respect to old age. Aging (Milano) 12: 461-469

Jacobs DR, Mebane IL, Bangdiwala SI, Criqui MH, Tyroler HA (1990) High density lipoprotein cholesterol as a predictor of cardiovascular disease mortality in men and women: the follow-up study of the Lipid Research Clinics Prevalence Study. Am J Epidemiol 131: 32-47

Kromhout D (2001) Diet and cardiovascular disease. J Nutr Health Aging 5: 144-149

Lifestyle-Related Diseases Control Health Service Bureau (2000) Kokumin-Eiyou-no-Genjo (Current Status of National Nutrition). Dai-ichi- Shuppan, Tokyo, Chapter 1,74

Marrugat J, Elosua R, Covas MI, Molina L, Prat JR (1996) Amount and intensity of physical activity, physical fitness, and serum lipids in men. The MARATHOM investigators. Am J Epidemiol 143: 562-569 
McCarron DA, Reusser ME (1996) Body weight and blood regulation. Am J Clin Nutr 63: 423-425

Ministry of Health and Welfare (1999) Abridged Life Table for Japan 1998. Statistics and Information Department Minister's Secretariat, Tokyo, Chapter 3, 16

Nagasaki Prefectural Government (1998) Vital Statistics of Nagasaki Prefecture. Division of Health and Welfare, Nagasaki, Chapter 3, pp. 165-167

Pietinen P, Koski ML, Vertiainen E, Puska P (2001) Nutrition and cardiovascular disease in Finland since the early 1970s: a success story. J Nutr Health Aging 5; 150-159

Pietrobelli A, Lee RC, Capristo E, Deckelbaum RJ, Heymsfield SB (1999) An independent, inverse association of high-density-lipoprotein-cholesterol concentration with nonadipose body mass. Am J Clin Nutr 69: 614-620

Salomaa VV, Jauhiainen M, Pietinen P, Korhonen HJ, Kartovaara L, Vartiainen E, Tuomilehto J (1991) Fiveyear trend in serum HDL-lipoprotein cholesterol in the Finnish population aged 25-64 years. A suggestion of an increase. Atherosclerosis 86: 39-48

Science and Technology Agency, Japan (1986) Standard tables of food composition in Japan (4th edition), Tokyo

Tanaka H (1992) The Protocol of a Nation-Wide Epidemiological Survey by the Japanese Lifestyle Monitoring Study. The National Institute of Health and
Nutrition, Tokyo

Tanihara S, Ojima T, Nakamura Y, Yanagawa H, Yoshiike N, Nakayama T, Tanaka H, the Japanese Lifestyle Monitoring Study Group (1999) Association between health-related knowledge and the awareness of blood pressure readings. J Epidemiol 9: 243-253

Taylor HL, Jacobs Jr DR, Schucker B, Leon AS, Debacker G (1978) A questionnaire for the assessment of leisuretime physical activities. J Chron Dis 31: 741-755

Tsuda T (1981) Narao-Cho-Kyoudo-Shi. Narao-ChoKyoudo-Shi-Hensan-Iinkai, Nagasaki, Chapter 5, 205

Yoshiike N, the Japan Lifestyle Monitoring Study Group (1997) The study on lifestyle monitoring in Japanese sample (abstract). J Epidemiol 1997, 7, 81

Yoshiki T (1983) Narao-Gyogyo-Hattatsu-Shi. Kyusyu University, Fukuoka, 342-343

Wilcox S Medina DP, Robinson MT, Will J (2001) Nutrition and physical activity intervention to reduce cardiovascular disease risk in health care settings: a quantitative review with a focus on women. Nutr Rev 59: $197-214$

Received: August 29, 2001

Accepted: October 10, 2001

Correspondence to: Kazuhiko Moji, Nagasaki University School of Health Sciences, 1-7-1 Sakamoto, Nagasaki 852-8520, Japan.

e-mail: moji-k@net.nagasaki-u.ac.jp 